\title{
Experiências de solidão entre os idosos que moram sós
}

\author{
Experiences of solitude among elderly who live alone \\ Experiencias de solitud entre ancianos que viven solo
}

\begin{abstract}
RESUMO
Objetivo: compreender as experiências de solidão entre os idosos que moram sós. Método: estudo exploratório de abordagem qualitativa, desenvolvido na zona urbana de Cuiabá-MT. Trinta e cinco idosos participaram deste estudo. Os dados foram coletados por meio de entrevista semi estruturada, escala de Lawton e Brody e o Índex de Katz, analisados pela técnica de análise temática. Resultados: envelhecer e viver em sociedade são processos naturais para idosos, envelhecer com autonomia e independência é desafiador. Morar só é uma condição nova vivenciada por eles, mas, a solidão não é própria da sua natureza. A construção dessa realidade revelou um sentimento de solidão que os ataca em diferentes intensidades a depender da fragilidade dos relacionamentos e do vínculo social. Conclusão: entende-se que a sociabilidade permite a integração dos idosos com outras pessoas, e que é importante a rede de apoio social e familiar que os ajudam nessa experiência de morar só.
\end{abstract}

DESCRITORES: Idoso; Solidão; Envelhecimento.

\section{ABSTRACT}

Objective: to comprehend the experiences of solitude among elderly who live alone. Method: exploratory study of qualitative approach, developed in the urban area of the of Cuiabá-MT. Thirty-five elderly participated of this study. The data were collected using script of interview, Lawton and Brody Scale and Katz Index and analyzed by the thematic analysis technique. Results: to age and live in society are natural processes to elderly. Living alone is a new condition experienced by them, but the solitude is not of their nature. The construction of this reality revealed a feeling of solitude that attacks them with different intensities depending of the fragilities of the relationships. Conclusion: it is understood that the sociability allows the integration of the elderly with other people and that the net of social and family support is important to help them in this experience of living alone. DESCRIPTORS: Elderly; Solitude; Aging.

\section{RESUMEN}

Objetivo: comprehender las experiencias de solitud entre los ancianos que viven solo. Método: estudio exploratorio de abordaje cualitativa, desarrollado en la zona urbana de Cuiabá-MT. Treinta y cinco ancianos participaran de este estudio. Los datos fueron recolectados usando guía de entrevista, la Escala de Lawton y Brody y Índex de Katz y analizados por la técnica de Análisis Temática. Resultados: envejecer y vivir en sociedad son procesos naturales para ancianos. Vivir solo es una condición nueva para ellos, pero la solitud no es propia de su naturaleza. La construcción de esta realidad reveló un sentimiento de solitud que los ataca en diferentes intensidades a depender de la fragilidad de los relacionamientos. Conclusión: se entiende que la sociabilidad permite la integración de los ancianos con otras personas y que es importante la red de apoyo social y familiar que los ayuden en esta experiencia de vivir solo.

DESCRIPTORES: Ancianos, Solitud, Envejecer.

RECEBIDO EM: 29/08/2020 APROVADO EM: 14/09/2020

\section{Roselma Marcele da Silva Alexandre Kawakami}

Enfermeira. Especialista em Auditoria dos Serviços de Saúde. Especialista em Vigilância em Saúde. Mestra do Programa de Pós-Graduação em Enfermagem da Universidade Federal de Mato Grosso. Atualmente docente no Centro Universitário UNIVAG.

ORCID: 0000-0001-5581-8115 


\section{Rosemeiry Capriata de Souza Azevedo}

Enfermeira, Doutora em Enfermagem Universidade Federal de Mato Grosso (UFMT).

ORCID: 0000-0001-7986-5768

\section{Annelita Almeida Oliveira Reiners}

Enfermeira, Doutora em Enfermagem Universidade Federal de Mato Grosso (UFMT).

ORCID: 0000-0002-5699-8215

\section{Natália Araújo de Almeida}

Enfermeira, Mestra do Programa de Pós-Graduação em Enfermagem da Universidade Federal de Mato Grosso (UFMT).

ORCID: 0000-0003-3435-7895

\section{Idilaine de Fátima Lima}

Enfermeira, Mestra do Programa de Pós-Graduação em Enfermagem da Universidade Federal de Mato Grosso (UFMT). ORCID: 0000-0001-8956-8097

\section{Luciane Cegati de Souza}

Enfermeira. Especialista em Auditoria nos Serviços de Saúde. Mestra do Programa de Pós Graduação em Enfermagem. Universidade Federal de Mato Grosso (UFMT).

ORCID: 0000-0003-0206-3075

\section{INTRODUÇÃO}

A tualmente é crescente a proporção de pessoas com 60 anos e mais que moram sozinhas. No mundo essa condição é vivenciada por $14 \%$ dos idosos, nos países da América do Norte e Oceania a média é acima de 25\%, na Europa varia de 10 a 25\%, ${ }^{1}$ e no Brasil 14,4\% desses indivíduos residem sós. ${ }^{2}$

Entende-se que morar sozinho é uma condição posterior, porque, desde o nascimento vivemos e precisamos de pessoas para prestar cuidados essenciais à sobrevivência. ${ }^{3}$ Entretanto, morar só traz repercussões para a vida dos idosos, como o aparecimento de tristeza, solidão e doenças, que afetam sua qualidade de vida, se tornando um problema para a saúde pública.

A literatura mostra que na Itália, idosos que moram só apresentaram menor disponibilidade de assistência pessoal e maior risco para ter depressão. ${ }^{4}$ Em Cingapura, esses idosos também estão propensos a sentir solidão e ter sintomas depressivos. ${ }^{5}$ Essa realidade é semelhante para idosas que moram sós em Taiwan. ${ }^{6}$ Além disso, idosos que moram sozinhos apresentam 1,81 vezes mais chance de consumir e usar antidepressivo do que os que moram acompanhados. Esses idosos podem ter o risco aumentado de desenvolver problemas relacionados à saúde mental e psicossocial.?

Estudo mostrou que idosos que vivem sozinhos tem menor satisfação com a vida e apresentam baixos níveis de apoio social. ${ }^{8}$ Soma-se a isso, o fato de que a ausência ou a redução do apoio podem afetar a vida deles em momentos de dificuldades.' A perda do suporte social, desordens cognitivas, depressão, múltiplas doenças crônicas, ocorrência de quedas e cefaléia de causa incerta, foram significativamente altas entre idosos que vivem sozinhos $(\mathrm{p}<0.05) .{ }^{10}$ Por outro lado, estudo realizado em Mallorca, na Espanha revelou que as famílias acreditam na preferência dos idosos em morar sozinhos devido conservação da sua liberdade e identidade individual. ${ }^{11}$ Morar sozinho pode significar uma escolha do idoso para promover a manutenção da capacidade funcional, ocasionando uma vida mais independente. ${ }^{12}$

Nesse sentido, são favoráveis as contribuições das ciências sociais e humanas para a produção científica na área de gerontologia, com a abordagem de conceitos como a sociabilidade que trás a ideia de unificar as pessoas, sendo construída no campo da experiência e realizada caso a caso. Das relações sociais que tratam da parte pessoal de cada um e da socialização que corresponde ao comportamento das pessoas de uma sociedade.13 Essas abordagens facilitam a compreensão dos apoios que são disponíveis para os idosos durante sua experiência de morar só. Além disso, contribui para reformular medidas que combatem a solidão que ataca esses indivíduos.

Afinal, a solidão surge quando não se tem alguém para trocar afetos, mas, pode ser mi- nimizada com estratégias de interação com as pessoas.14 Nesse sentido, é importante que esses idosos tenham uma rede de apoio que promova o cuidado. Com relação aos estudos sobre idosos que moram sozinhos, percebeu-se que os resultados incluíam a questão da solidão. Por ser um tema importante na gerontologia, pouco se conhece a realidade da solidão a partir da perspectiva deles. ${ }^{6} 15-17$ Sendo assim, este estudo objetivou compreender as experiências de solidão entre os idosos que moram sós.

\section{MÉTODO}

Pesquisa exploratória de abordagem qualitativa, desenvolvida na zona urbana do município de Cuiabá-MT. Os participantes eram idosos que participaram da pesquisa sobre as condições de vida da população idosa do município de Cuiabá-MT.18 Dos 573 idosos desse estudo, 57 referiram morar sozinhos. Buscamos encontrar todos eles, entretanto, 8 foram a óbito e 4 mudaram de endereço. Dos 45 restantes, 5 deixaram de morar sozinhos e 1 se recusou a participar do estudo. Foram incluídos na pesquisa aqueles que, no momento da coleta de dados, estavam em condições de compreender e responder as perguntas mediante avaliação do Mini Exame do Estado Mental (MEEM), 4 foram excluídos após aplicação do MEEM. Ao final, 35 idosos participaram desta pesquisa e assinaram o termo de consentimento livre e esclarecido (TCLE). 
Os dados foram coletados no domicílio dos idosos no período de março a maio de 2014 por meio de um único encontro, com a realização da entrevista semi-estruturada, utilizando roteiro contendo questôes sobre a experiência de morar sozinho para os idosos, a Escala de Lawton e Brody e o Índex de Katz. As entrevistas foram gravadas, transcritas na íntegra e o material organizado e realizado análise temática. A pesquisa foi aprovada pelo Comitê de Ética em Pesquisa do Hospital Universitário Júlio Muller (CEP-HUJM), por meio do protocolo $\mathrm{n}^{\circ} 527.935 / 2014$, com o Certificado de Apresentação para Apreciação Ética (CAAE) nº 26520714.2.0000.5541.

\section{RESULTADOS}

A maioria dos idosos era do sexo feminino, viúvos, com idade entre 63 a 85 anos, tinham entre dois ou mais filhos e todos se relacionavam com familiares ou amigos. A experiência de morar só revelava a necessidade do outro e a importância de laços para manter a comunicação e afetos que possibilitavam a realização da felicidade. Todavia essa experiência também possibilita o surgimento da solidão. Nota-se essa evidência por meio dos discursos:

[...] Chega uma pessoa en fico feliz, eu gosto, eu falo ô ninguém vem na minha casa conversar comigo pra me distrair. [...] Eu gosto que venha gente na minha casa. (Morando só) aprendi a conversar com as pessoas (Idosa 2).

É ruim ficar sozinha sem ter uma pessoa pra conversar. Eu gosto de conversar, brincar com as crianças. [...] Eu não sou apegada, mas tem dois vizinhos que vou deu vontade de ir eu vou, às vezes recebo visita, esses tempos atrás minha casa era cheia de gente. [...] Ondepassei deixei amizade. Eume arrependi de ter aposentado, ficar sozinha em casa. Ah, no começo tinha meus filhos, era dedicada muito a eles, agora depois que eles casaram que fiquei só eu acho assim chato ficar sozinha, se quer conversar e não pode. Você sente aquela tristeza de ficar só. [...] A gente se sente assim, muito só. [...] Ai às vezes eu saio vou passear, ai outra hora vou à casa da outra menina (Idosa 3).

O fato de os idosos deste estudo habitarem sós não significa que se sintam sozinhos. Apesar de vivenciar esta condição, alguns mantêm o convívio social se relacionando principalmente com familiares, amigos, vizinhos e animais de estimação.

[...] Meu neto começou a ficar comigo, minha neta traz ele as 11:30, e pega ele às 17:30. [...] foi uma coisa de Deus. Nossa, ele é uma companhia pra mim, apesar da bagunça que ele faz. Nossa! O cachorro também, esse Pepe (cachorro) eu ganhei de um menino que era vizinho, eu tenho uma gatinha a Kelly. Além disso, eu vou sempre à casa dos meus irmãos, eles também vem aqui (Idosa 18).

Ah, os animais são uns companheiros maravilhosos, toda vida desde criança eu tive animal. Ele deita ali, eu não grito com nenhum, falo da licença que eu to passando. Eu dou banho, toso, a mamãe gosta dos meninos (Idosa 15).

Por outro lado, para outros idosos que moram sozinhos a ausência de outras pessoas no domicílio para conversar e trocar afeto tem gerado o sentimento de solidão, que pode ser temporário ou permanente. No entanto, quando a solidão é constante na vida deles, traz consequências, como, isolamento social e depressão, o que pode afetar a qualidade de vida e saúde da pessoa idosa, bem como a condição de morar só.

[...] Solidão é ruim, você fica sozinha, solitária, eu fico mais assistindo televisão [...] Eu já sofri de depressão, tomava remédio controlado, ficava deitada, aí eu não conseguia recuperar minha saúde, ai eu fui pra casa da minha irmã, ai fiquei um ano lá eu recuperei, aqui eu ficava muito sozinha [...] muito sozinha, ai a depressão pegou. [Hoje] Fico sozinha, solitária, e tomo remédio pra dormir [...] Pra falar a verdade eu não me sinto sozinha, só a noite que eu fico sozinha, ai quando eu me sinto sozinha aqui eu saio lá pra frente, converso com meus vizinhos e assim eu vou levando. (Idosa 8)

Na medida em que eles continuam residindo sozinhos e estabelecem e/ou mantém relações de afeto, carinho e ajuda com familiares e pessoas do entorno, passam a habitar só, mas, não a viver só. Neste grupo de idosos, o sentimento de solidão é ausente ou temporário, uma vez que, as relações sociais e o apoio que recebem preenchem suas necessidades. Conforme o relato da Idosa 32:

[Morar sozinha] tem o lado da solidão, porque você tem dia sente. Mas, eu não tenho tempo para sentir solidão, eu to sempre em atividade, sempre fazendo alguma coisa, agora eu estava ligando para 20 pessoas, porque eu sou presidente de uma esmola do Divino, então eu não dou tempo de sentir a solidão.

É evidente que a relação com as pessoas contribui tanto no combate a solidão, quanto na realização das atividades cotidianas dos idosos neste estudo. Mesmo independentes, alguns deles recebem auxílio de outros para ir a locais distantes e fazer compras, ou ainda dentro do domicílio, como limpar e/ou organizar a casa.

Vou [ao centro espirita], quando vem gente me buscar, tem um rapaz que sempre me leva [...] Esses dias atrás não tinha mais as coisas pra eu fazer para comer, e eu estava com um dinheirinho ai, mas, não tinha ninguém, meu filho estava saindo de madrugada pra ir para o serviço, não tinha tempo para ir ao supermercado para mim, e eu ficava esperando minha sobrinha, que também estava ocupada com a amiga dela doente, e não podia estar vindo aqui, e eu fiquei passando falta, ai assim que ela apareceu ela foi e comprou pra mim. Eu tenho uma sobrinha que vem aqui, ela passa pano, tira oforro, troca tudo pra mim. [...] [Além disso], A gente não gosta [de morar só], porque às vezes a gente precisa de uma pessoa pra 


\section{artigo}

conversar, pra distrair, e a gente ficando sozinh a a gente fica pensando muita bobagem. Sinto falta dos meus filhos, principalmente na hora de eu comer, quero sempre que tenha um filho tomando um café comigo, ou então almoçando comigo, então me visitando (Idosa 9).

Os idosos deste estudo vivenciaram um descompasso em termos de suporte social. A fragilidade nas relações, que eram insuficientes e pouco afetivas não atendiam as reais necessidades deles, possibilitando o surgimento da solidão.

$E$ Éruim morar sozinha], não tem com quem conversar, a gente fica inválido, não tem ninguém pela gente. [...] Não tem ninguém para conversar com você, é ruim de mais (Idosa 4).

Além disso, a solidão também pode ser influenciada por características pessoais daqueles que preferiram morar só. Ao longo da vida a individualidade pode fazer com que as pessoas evitem a profundidade dos relacionamentos. Fato evidenciado no discurso:

Você quer conversar e não pode, você sente aquela tristeza de ficar só, a gente sente assim muito só. Eu sou meio difícil, eu nunca gostei de estar compartilhando as coisas, ai eu fiquei morando sozinha [risos]. Muita gente fala que [morar só significa] solidão, não gosto de ficar sozinho, porque é solidão, pra mim não é, pra mim é um alivio, eu gosto de ficar sozinha com meus pensamentos, prefiro sozinha (Idosa 14).

Além disso, a perda ou diminuição dos relacionamentos levaram os idosos desse estudo a sentirem-se só. Nota-se isso por meio do discurso:

Às vezes você esta triste, não da pra sair sozinha, vocêpensa eu queria ir a tal lugar, mas não vou não sozinha, no outro dia vocêamanhece bem. (Idosa 17)

Sabe que me ataca a solidão é quando vai chegando o entardecer e eu tenho que fechar toda a casa, e eu não vejo ninguém. Choro ao entardecer todos os dias ao lembrar o meu esposo falecido. (Idosa 20)

Dessa forma, percebe-se que apesar da escolha de morar só e de gostar desta condição, ou da insuficiência de relacionamentos, é preciso fortalecer a rede de apoio para evitar sentir solidão. Nesse sentido a saúde da família é de extrema importância no fortalecimento da rede de apoio e de atenção à saúde a esses indivíduos, ampliando ações de socialização e efetivando o grupo de pessoas idosas nas unidades de saúde da família, a fim de prestar um suporte social a esses idosos.

\section{DISCUSSÃO}

Idosos solitários necessitam de estratégias de saúde que envolvam serviços sociais ${ }^{19}$. Dessa forma, entende-se que intervenções integradas realizadas em grupo e ludoterapia são atividades consideradas efetivas para aumentar funções cognitivas e reduzir níveis de depressão em pessoas idosas que moram sozinhas ${ }^{20}$.

Entretanto, a realidade de idososem Cingapura mostrou que há idosos que recusam ou deixam de buscar ajuda de família e amigos na sociedade, pois, consideram que essas atitudes representam um fardo para eles, pois, esse tipo de situação afeta a vida de outros pessoas, como ter que deixar de trabalhar para cuidar da pessoa idosa ${ }^{21}$.

Outro estudo realizado na China mostrou que $43 \%$ da população idosa chinesa sofrem de depressão. Os fatores relacionados a maior risco de depressão foram eventos negativos com a família. Morar só aumentou $56 \%$ o risco de sintomas depressivos comparado as pessoas que moravam com outros sem situações negativas. As pessoas idosas sem conjugue também apresentaram maior risco para depressão $0^{22}$.

Idosos vivendo sozinhos na China Continental foram considerados mais vulneráveis a solidão, uma vez que, a baixa escolaridade e condição financeira aumentam o risco de solidão, além disso, eles têm menor apoio social. ${ }^{23}$ Em um estudo realizado na Itália, as más qualidades de vida dos idosos que moram só eram influenciadas pelas condições financeiras, de saúde e especialmente as relações sociais.4

Resultado de um estudo mostrou que as mulheres idosas que moravam sozinhas porque os filhos se casaram, sentiam uma solidão que é passageira e pontual, por saber que não tinha sido abandonada e poderia contar com a ajuda do filho caso necessário, no entanto, a solidão se agrava quando ela é abandonada pelo marido e as lembranças dessa relação lhes causam sofrimento ${ }^{24}$. Nesse sentido, entende-se que "a tristeza do idoso sempre vem acompanhada de muitas perdas que ele tem que enfrentar ao longo de sua existência, e que querendo ou não tem que se acostumar com esse processo, acaba chegando um tempo que precisa conformar-se em viver sozinhos" 25 .

O sentimento de solidão relatado pelos os idosos do presente estudo revela que a velhice perpassa por experiências individuais e pelas as relações de vínculos que são construídas no âmbito da família e da comunidade. A fragilidade na rede apoio dos idosos que moram sozinhos pode resultar no comprometimento da saúde física e emocional. Considerando esse contexto da literatura, entende-se que os profissionais da saúde coletiva precisam realizar ações para evitar a solidão, considerando a importância dos relacionamentos, da promoção da saúde e da inclusão social.

\section{CONCLUSÃO}

Viver de forma independente e habitar só no domicílio é uma tendência para idosos. Entretanto a solidão vivenciada por eles não é natural do envelhecimento. Por essa razão, compreende-se a importância da sociabilidade no combate ao sentimento da solidão, no sentido de agregar pessoas para o cotidiano do idoso que mora só.

Mediante esse contexto, entende-se que a solidão ataca os idosos de forma temporária, e para outros de modo prolongado. Ao notar os ataques da solidão nos idosos da comunidade, faz-se necessário que as pessoas de modo geral compreendam a importância de criar ou manter vínculos no processo de envelhecimento e em todas as fases da vida, com intuito de afastar a solidão na velhice.

Acredita-se que uma das principais medidas a ser tomada no combate a solidão são os investimentos em educação e socialização. No sentido de formar pessoas conscientes da importância dos hábitos de vida saudáveis e do relacionamento interpessoal para a qualidade de vida.

As pessoas precisam entender que mesmo vivendo independente em seu domicílio é importante e essencial receber o suporte adequa- 
do. Destaca-se que entre profissionais da área da saúde e sociais, especialmente o enfermeiro precisa estar preparado para lidar com a diver- sidade das demandas em saúde, principalmente no tocante às questões sociais e psicológicas dos idosos, por se tratar de indivíduos da co- munidade que utilizam serviços públicos de saúde, considerando a estratégia saúde da família a porta de entrada desses serviços.

\section{REFERÊNCIAS}

1. United Nation Department of Economic and Social Affairs. Population Division. Living Arrangements o folder Persons Around the World. New York, 2005. Disponivel em: http://www.un.org/esa/ population/publications/livingarrangement/report.htm Acessado em: 10/06/2013

2. Ibge Instituto Brasileiro de Geografia e Estatística. Síntese de Indicadores Sociais: Uma Análise das Condições de Vida da População Brasileira. Estudos\& Pesquisas. Informação Demográfica e Socioeconômica 29. Rio de Janeiro, 2012.

3. Camargos MCS. Enfim só: um olhar sobre o universo de pessoas idosas que moram sozinhas no município de Belo Horizonte (MG), 2007. Tese de Doutorado em Demografia do Centro de Desenvolvimento e Planejamento Regional da Faculdade de Ciências Econômicas da Universidade de Minas Gerais. Belo Horizonte, Minas Gerais, 2008.

4. Bilotta C, Bowling A, Nicolini P, Casè A and Vergani C. Quality of life in older outpatients living alone in the community in Italy. Health and Social Care in the Community. 2012. 20 (1), 32-41.

5. Lim LL, Kua EH. Living Alone, Loneliness, and PsychologicalWell-Being of Older Persons in Singapore. Current Gerontology and Geriatrics Research. Article. 2011. p. 9.

6. Lin PC, Wang HH. Factors associated with depressive symptoms among older adults living alone: An analysis of sex difference. Aging \& Mental Health, 2011; 15:8, 1038-1044.

7. Pulkki-Raback L, Kivimaki M, Ahola K, Joutsenniemi K, Elovainio M, Rossi $\mathrm{H}$, et al. Living alone and antidepressant medication use: a prospective study in a working-age population. Finlândia. BMC Public Health. 2012. 12:236.

8. Kooshiar H, Yahaya N, Hamid TA, Samah AA, Jou VS. Living Arrangement and Life Satisfaction in Older Malaysians: The Mediating Role of Social Support Function. Plos One. 2012. Volume 7. Issue 8 e 43125.

9. Ramos JLC, Menezes MR, Meira EC. Idosos que moram sozinhos: desafios e potencialidades do cotidiano. Revista Baiana de Enfermagem, Salvador. v. 24, n. 1. 2. 3. 2010; p. 43-54.

10. Mouodi $S$ et al. Gender differences in the health status of elderly living alone compared to those who are not alone: Evidence of the AHAP study, North of Iran. Caspian J Intern Med 2016; 7(2):126-132.

11. Molina-Mula, J; Gallo-Estrada, J; Miquel-Novajra, A. Attitudes and beliefs of Spanish families regarding their family members aged 75 years and over who live alone: a qualitative study. BMJ Open 2019; 9

12. Perseguino, MG; Horta, ALM; Ribeiro, CA. A família frente a realidade do idoso de morar sozinho. Revista Brasileira de Enfermagem. 2017; 70(2):251-7. DOI: https://doi.org/10.1590/00347167-2016-0398
13. Araújo CAA. Imaginação e Sociabilidade: novos conceitos para o estudo de usuários da informação. XVI Encontro Nacional de Pesquisa em Ciência da Informação. Outubro, João Pessoa-PB, 2015.

14. Camargos MCS, Rodrigues RN, Machado CJ. Percepção da solidão entre idosos residentes em domicílios unipessoais no município de Belo Horizonte. Texto para discussão n³77. Dezembro. UFMG/Cedeplar. Belo Horizonte, 2009.

15. Chan A, Malhotra C, Malhotra R, Ostbye T. Living arrangements, social networks and depressive symptoms among older men and women in Singapore. Int J Geriatr Psychiatry 2011; 26: 630-639.

16. Tong HM, Lai DWL, Zeng Q, Xu WY. Effects of social exclusion on depressive symptoms: Elderly Chinese Living Alone in Shanghai, China. J Cross Cult Gerontol. 2011. 26:349-364.

17. Wang J, Zhao X. Family functioning and social support for older patients with depression in an urban area of Shanghai, China. Archives of Gerontology and Geriatrics. 2012; (55) 574-579.

18. Louzada CV. Condições de vida da população idosa do município de Cuiabá, Mato Grosso. 2013. 123 f. Dissertação (Mestrado em Enfermagem) - Faculdade de Enfermagem. Universidade Federal de Mato Grosso. Cuiabá, 2013.

19. Negrini ELD, Nascimento CF, Silva A, Antunes JLF. Quem são e como vivem os idosos que moram sozinhos no Brasil. Rev. Bras. Geriatr. Gerontol., Rio de Janeiro, 2018; 21(5): 542-550.

20. Kil T, Yoon K, Ryu H, Kim M. Efeito do programa de intervenção integrada de grupo combinado com terapia assistida por animais e ludoterapia integrada para idosos que vivem sozinhos. J. Anim Sci Technol. Novembro de 2019; 61 (6): 379-387. DOI: 10.5187 / jast.2019.61.6.379

21. Lee JMG, Chan CQH, Low WC, Lee KH, Low LL. Health-seeking behaviour of the elderly living alone in an urbanised low-income community in Singapore. Singapore Med J 2020; 61 (5): 260-265. DOI: https://doi.org/10.11622/smedj.2019104

22. Wang, Z., Yang, H., Zheng, P. et al. Eventos negativos na vida e sintomas depressivos: a pesquisa social do envelhecimento longitudinal na China. BMC Public Health 20, 968 (2020). https://doi. org/10.1186/s12889-020-09119-0

23. Chen Y, Hicks A, While AE. Loneliness and social support of older people living alone in a county of Shanghai, China. Health and Social Care in the Community. 2014; 22(4): 429-438.

24. Bispo R. Retratos da solidão: sofrimentos e moralidades femininas na velhice. Soc. e Cult., Goiânia, v. 17, n. 1, p. 41-50, jan./ jun. 2014.

25. Vieira AC. Envelhecimento e solidão em Parintins: uma análise das condições de vida e saúde dos idosos residentes nos bairros Itaúna I e II. Universidade Federal do Maranhão(UFMA).VII Jornada Internacional de Políticas Públicas. Para Além da Crise Global: experiências e antecipações contretas, 25 A 28 de agosto de 2015. 